\title{
Conceptual Framework for Growth Triangles
}

\author{
M. AYNUL HASAN
}

\section{INTRODUCTION}

\section{An Overview}

In recent years, while the significance of regional trade and trading blocs within Asia region (AFTA, APEC, ASEAN, SAARC, EAEC, etc.) has gained considerable interest among the policy-makers and researchers alike, tangible accomplishments, in terms of enhanced economic cooperation and trade liberalisation among the trading blocs, are still muted [Thant et al. (1998), p. 23]. Several reasons and problems have been cited for the limited success of these formal trading blocs, particularly in the Asia region, namely:

(a) shortage of large volumes of internal and inter-regional trade;

(b) absence of complimentary laws and regulations among the trading blocs in managing trade and investment flows;

(c) inadequate transport and communication facilities and the lack of geographic proximity among many member countries;

(d) presence of income disparities among several member countries may have negative effect on income distribution at the time of adjustments in trade flow; and

(e) lack of political commitments and policy coordination among member countries.

However, since the late 1980s, a new innovative genre of regional economic cooperation, bridging the differences between regional blocs and international trade, began to surface in the Asia region, which are now commonly known as "growth triangles" or, more appropriately, "growth zones" be devoid of some of the predicaments noted above for regional trading blocs. ${ }^{2}$ In

M. Aynul Hasan is Chief, LDCs Section, Development Research and Policy Analysis Division, UN-ESCAP, Bangkok.

Author's Note: The author wishes to thank Drs Azizul Islam and Hiren Sarkar for useful discussions on the paper. The views expressed in the paper are those of the author and do not necessarily reflect the views of the United Nations.

${ }^{1}$ It should be noted that growth triangles may also encompass "subregional economic zones", "natural economic territories" or "extended metropolitan regions" [e.g., see Chia and Lee (1992); McGee and Macleod (1992)]. In this paper, however, both "growth triangles" and "growth zones" will be used interchangeably.

${ }^{2}$ For a detailed discussion on growth triangles, reader may refer to Hasan (2000). 
general, these growth triangles evolved independent of each other; they did not coerce an elaborate formal alteration in national institutional and administrative establishments; and, more importantly, unlike the trading blocs, they usually appertained only to segments of two or more contiguous participating member countries.

\section{Key Ingredients for the Success of Growth Zones}

While there are several elements that may facilitate the successful operation of growth zones, based on the experiences of some of the existing zones (Southern China, JSR, IMT, BIMP-EAGA etc.), four factors are generally considered important [Thant et al. (1998)]. These factors are:

(a) Economic Complementarity: Essentially, economic complementarity emanates from the participating member region's varying phases of development as well as asymmetric distribution of factor endowments. Economic complementarity may also arise due to asymmetry in terms of technology and the quality of human capital endowments available to each participating members in the growth zone.

(b) Geographic Proximity: With respect to geographic proximity, many researchers have argued and empirically demonstrated, that it plays a dominant role for countries to engage in international trade [Frankel and Romer (1999); Summers (1991)]. The fact that two countries or regions are far apart from each other may entail higher cost of transportation and communication which could otherwise be minimised if they are located at close proximity.

(c) Political Commitment and Policy Coordination: While growth zones may offer more flexibility compared to some of the formal rigid requirements of regional trading blocs, the role of political government and policy coordination is, nevertheless, quite pivotal in the success of growth zones. Various macroeconomic, trade and labour policy directives and initiatives need to be supported and coordinated among the various levels of governments. Implementation of such policies will obligate strong political commitments and, at times, may require foregoing "some measure of sovereignty" [Thant et al. (1998), p. 44].

(d) Infrastructure Development: The role of infrastructure development for the success of growth zones cannot be overemphasised. While the low cost of labour and international mobility of capital are critical, equally important is the establishment of adequate physical infrastructure facilities in terms of power, roads, ports, and harbors.

Instituting regional economic cooperation, growth zones are thus expected to promote further allocative efficiency of resources, cultivate international competitiveness, and encourage growth. The popularity of growth zones is 
accentuated by the fact that, unlike the trading blocs, they can be ensconced at a comparatively low cost as well as within a short span of time. Thus, it is the international mobility of capital (in terms of FDI) combined with low cost of labour and involvement of contiguous regions of more than one country that make growth triangles far more attractive and competitive as compared to traditional regional blocs. Not only that, the successful benefits of the growth zones may be augmented to the other parts of the region while the detrimental repercussions (such as liberalisation) can be confined in the adjacent areas of the zones. Apart from these, there are other non-economic forces that may also provide impetus to the success of growth zones in the Asia region such as, strong ethnic identity, common language, long historical ties, similar cultural values, etc.

With the abovementioned brief overview of growth zones, it will be useful to provide some examples and lessons learned from the exiting growth triangles in Asia region. This may not only help in understanding the operational dynamics and procedures of existing growth zones in terms of their success and limitations, but more importantly, it may also provide information for the establishment of potential growth zones in other parts of the region, particularly South Asia. As an example, the next section is devoted to the discussion of the Southern China growth triangle.

\section{EXAMPLES FROM SOUTHERN CHINA GROWTH TRIANGLE}

The Southern China growth triangle is the oldest and most successful among the existing growth zones. It comprises Hong Kong, China; Taiwan province of China; and four special economic zones (SEZ) in the Southern part of the Peoples Republic of China (Shantou and Zhuhai in Guangdong, and Xiamen in Fujian). It is interesting to note that, this growth zone has been operating successfully despite the participating member regions' marked divergence in their respective political system as well as differences in the stages of economic development.

Economic complementarity, in terms of differential factor endowments, close geographic proximity, the dynamic private sector initiatives and governments' supportive role have made this economic integration viable. For instance, Hong Kong, China and Taiwan Province of China have a fervent industrial sector, welldeveloped financial markets, fairly advanced infrastructure facilities and well-trained labour forces. On the other hand, shortage of unskilled labour and paucity of land in these regions have caused escalation in labour costs and hike in property prices, thus reducing competitiveness of their exports in the international markets. In contrast, the Southern part of Peoples Republic of China's (PRC) participating regions lack both capital and managerial skills but have an abundant supply of both labour and land. At the same time, PRC's introduction of open-door policy and the formation of the SEZs provided added impetus to the investors from Hong Kong, China and Taiwan Province of China to relocate their labour intensive industries to Southern 
China for the diversification and rationalisation of their production. This economic cooperation made the Southern China growth triangle viable and mutually beneficial to all participating member regions.

In order to get a deeper insight into the success of Southern China growth triangle, a brief discussion of some of the success factors for each of the participating members as well as the associated problems and prospects are given.

\section{Prospects for Economic Complementarity}

\section{Hong Kong, China}

It provides a well developed and enriched class of entrepreneurs which is the key to economic development. The entrepreneur group flourished in Hong Kong, China mostly due to stable political environment and consistent economic policies pursued by the colonial government [Chen and Lee (1998)]. Apart from a well developed physical infrastructure, advanced technology and efficient financial sector, Hong Kong, China has a large pool of "soft technology" in the services sector. This last factor has enabled Hong Kong, China to become one of the leading players in the world financial market since the 1970s. Some of the other government policy initiatives that also backed Hong Kong, China , in this context, are: (a) no differential treatment between local and offshore markets; (b) least government control with highly unregulated market; (c) low taxation; and (d) stable currency linked to US dollar.

On the other hand, Hong Kong, China faces shortage of both domestic labour and land. Labour shortage is due to changing demographic features, high economic growth and, to some extent, emigration. While, in the past, large inflows of cheap labour from PRC has helped Hong Kong, China to maintain its competitive edge in the manufacturing sector, since the 1980s, the adoption of strict legal immigration laws has abated the flow of those workers. Consequently, the share of labour intensive manufacturing industries to GDP has contracted in the past two decades and there are only 376,000 workers employed in the manufacturing sector in 1995 as opposed to over a million workers in 1980 [Wong (1992)]. Not only that, there is also about 10 percent out migration of workers from the manufacturing sector each year.

Thus, in view of the factor cost differential and economic complementarity as well as to avert import quotas levied by the developed countries, Hong Kong, China, in the 1970s, initiated the process of relocating its manufacturing to the Southern regions of PRC. ${ }^{3}$

\section{Taiwan Province of China}

It is interesting to note that Taiwan Province of China's economic complementarity in the growth triangle comes from a restructuring within

${ }^{3}$ For example, in 1990 the monthly overall average wage of workers in Guangdong was only HK\$ 532 as opposed to HK\$ 6,182 in Hong Kong, China (Guangdong Statistical Bureau, Statistical Yearbook of Guangdong 1995). 
manufacturing sector which is notably different from that of Hong Kong, China where the financial sector played a critical role. Unlike Hong Kong, China, Taiwan Province of China still maintains a high proportion of manufacturing sector in GDP; 29 percent for Taiwan Province of China versus 9.3 percent for Hong Kong, China in 1994 [Taiwan Province of China Statistical Yearbook (1995)].

However, the restructuring of Taiwan Province of China's manufacturing was mostly restricted to the technology-intensive and capital-intensive sectors such as, electrical machinery, computers and computer peripherals, and electronic components. On the other hand, due to high labour costs and land value, the share of labour intensive and land intensive industries such as textiles, wearing apparel, and leather declined significantly, since the 1980s and, thus, relocated to the Southern region of PRC. On top of this, Taiwan Province of China had a comparative advantage in both "hard" and "soft" technology in the industry sector.

There were other factors such as large financial capital resulting from trade surplus since the 1980s and relatively less investment prospects available on the island that also motivated enterprising investors in Taiwan Province of China to venture opportunities abroad.

\section{South China's SEZ}

The prospects for economic complementarity of Southern region of PRC arise as a result of their copious and cheap labour and land. It should be noted that the rental cost of per square meter factory space in Shenzhen SEZ amounted to less than one-fifth that of New Kowloon, while the wage rate of the manufacturing sector in Shenzhen SEZ was only about one-tenth that of Hong Kong, China in $1994 .{ }^{4}$ Given that a substantial portion (about 75 percent) of the total labour force in the SEZ are predominantly involved in agriculture, this provided the opportunity to the Southern China growth triangle to draw from the large sources of labour force for the manufacturing sector.

In recent years, concerns have been expressed over the cost hike due to this alluring and dynamic production opportunities in the Southern China region, however, such increases in cost, to a large extent, have been counterbalanced by the depreciation of the yuan. In fact, during the period 1990 to 1995, the actual increase in prices has been 11.9 percent, while, during the same period, the depreciation of yuan vis-à-vis US dollar was as high as 10.5 percent. ${ }^{5}$ Not only that, the productivity of labour has also increased in the Southern China region since the 1990s.

Thus, the above discussion suggests that these three regions have distinct but divergent comparative advantages and economic complementarities. The growth

${ }^{4}$ Hong Kong, China Rates and Valuation Department, Hong Kong, China Property Market Review 1996; Hong Kong, China Census and Statistics Department, Monthly Digest of Statistics (June 1996); Guangdong Statistical Bureau, Statistical Yearbook of Guangdong 1995; SBC Warburg, The Asian Property Advisor, June 1996.

${ }^{5}$ Source: State Statistical Bureau of PRC. 
triangle has simply provided them with the opportunity to combine and harness them to their mutual benefit. In this context, it is important to note that, in 1994, Hong Kong, China alone had contracted investment to Guangdong in the amount of $\$ 18.74$ billion, while Taiwan Province of China's contracted investment in the same year has been to the extent of $\$ 850$ billion. $^{6}$

\section{Support of Government Policies}

Apart from economic complementarity and geographic proximity, the success of Southern China growth triangles is also predicated on the ardent support of the governments of PRC and Taiwan Province of China and Hong Kong, China. Since Hong Kong, China's policy initiatives were, in general, supportive to open trade and since it maintained close economic links with both PRC and Taiwan Province of China, in the following, some of the crucial policy initiatives taken by only PRC and Taiwan Province of China, which contributed towards success of the growth triangle, are presented.

\section{PRC Policy Initiatives}

(a) Four Modernisations: Modernisation of the four key sectors, namely, agriculture, industry, national defense, and science and technology became the overriding development principle for PRC in 1979. The consequence of such a change in policy focus in the PRC also meant to apostatising the earlier inward-oriented self-reliant and isolationist policies. Rather than digressing from the world market, the PRC confined its own constructive energies via administered imports of technology and fostering exports;

(b) Three Contacts: Based on the tenet of "Peaceful Unification", in 1979, the PRC embarked on a direct contact policy with Taiwan Province of China by means of mail, air and sea links and trade. Within the ambit of this policy initiative, the PRC also accorded preferential treatment to the business community from Taiwan Province of China while undertaking investments and other economic activities in the PRC;

(c) Establishment of Economic Zones: By 1980, four economic zones were set up with a preferential treatment accorded to them related to tax concessions, non-tariff incentives and subsidies. Complex bureaucratic procedures were simplified;

(d) Opening of Coastal Port Cities: In 1984, fourteen coastal port cities and Hainan Island were opened for foreign investments. Not only that, like SEZs, these port cities also provided preferential treatment to the investors; and

(e) Land Use Right: By 1987, Shenzhen Special Economic Zone was accorded land use right which, in a way, was a significant first step towards land use reform in the PRC.

${ }^{6}$ Source: Statistical Yearbook of Guangdong 1995. 


\section{Taiwan Province of China's Policy Initiatives}

Taiwan Province of China has also taken a number of important policy initiatives towards easing bans and establish contacts with the mainland, particularly after 1985, when import restrictions on PRC products were slowly liberalised.

(a) Government allowed indirect exports for a wide range of commodities while imports for a limited range of products were permitted in 1985 and 1987, respectively;

(b) Domestic entrepreneurs were allowed to invest abroad including in the mainland, particularly since 1987, when foreign exchange restrictions were dispelled and Taiwan Province of China nationals were permitted to visit PRC;

(c) Indirect investments in the mainland were ratified in 1991 by Taiwan Province of China's Ministry of Economic Affairs and the investors were invited to register them with the Ministry. This prompted a surge of registered investors to the extent of 2,750 by 1991 [Chen and Lee (1998)];

(d) By 1992, the Statute for Relations across the Taiwan Province of China Strait was passed which allowed broad based direct links with the mainland via air and sea. In addition, the law also permitted importation of workers from PRC which abated the paucity of labour in the domestic market;

(e) In 1992, the 40-year-old ban on banks on investing in the mainland was lifted by the Mainland Affairs Council; and

(f) The intention of converting Kaohsiung into a regional shipping base for Asia and the Pacific was announced by Taiwan Province of China in 1991. Proposals were also made to establish direct shipping links with mainland. However, political tensions across the Strait in early 1996 led to the abandonment of such initiatives.

\section{Challenges}

Some of the challenges that the Southern China growth triangle needs to address relate to overcoming political considerations, competition from other growth triangles, conflict in trade, evasion of controls, and inadequate transfer of technology and infrastructure planning.

While the economic links between Taiwan Province of China and the PRC have been increasing, the same cannot be said about the political relationship between the two countries, particularly after the recent tension in the waters of Taiwan Province of China Strait. There are apprehensions that an over dependence of Taiwan Province of China's economy on the PRC resources and labour may enable the latter to exert pressure on the investors of the former. ${ }^{7}$ On the other hand, Hong Kong, China's transition to "one country, two system" policy since 1997 have

${ }^{7}$ There are some evidences substantiating such a conjecture. For instance, the quantum of trade (re-export from the PRC to Taiwan Province of China) between the two countries fell by as much as 10.3 percent following the tension in the Taiwan Province of China Strait in 1996 [Chen and Lee (1998)]. 
so far worked well. However, concerns have been raised regarding the differences in legal and administrative systems between the two economies which might have a deleterious impact on the investors' confidence.

The second area of challenge pertains to the competition emanating from other growth zones from within and outside the region. As for within region growth zones, the Yangtze region, which consists of Shanghai and the six provinces along the middle-lower Yangtze River, namely, Jiangsu, Zhejiang, Hunan, Hubei, Jiangxi, and Anhui, could be a possible competitor to Southern China growth triangle. In recent years, opening up of the Pudong development zone in Shanghai to foreign investors through the PRC government's initiatives has attracted some foreign capital to this emerging growth zone. However, in this context, the general perception is that such an initiative is unlikely to deflect the existing or new investments from Southern China growth triangle to this new zone, as Hong Kong, China is likely to remain the hub of financial and high-tech manufacturing activities [Chen and Lee (1998)]. In terms of outside region, Johor-Singapore-Riau (JSR) growth triangle may pose the same challenges to the Southern China growth triangle. However, on the grounds of Hong Kong, China's geographic proximity as well as common ethnic and language considerations, the probable threat to Southern China growth zone from JSR is likely to be somewhat subdued.

Thirdly, probable trade frictions between the United States (US) and PRC may pose challenges to the Southern China growth triangle. Overdependence of all three economies in the growth triangle on the US export market (in terms of re-export and import facilities) may be a matter of concern, particularly in a situation where the US Government may revoke the most favoured nation status (MFN) currently granted to the PRC.

Fourthly, evasion of government rules and controls and yielding on the fair conduct of business practices may have debilitating consequences on the efficient operation and development of growth zones in the long run. False invoicing, bribery in licencing and smuggling are some of the few examples of evasion of government controls. The occurrences of such illicit practices (particularly in the form of fake invoicing) have been noted, especially during the trade from Hong Kong, China to the PRC, as the market system of the former is more flexible and open and due to its proximity to the latter (Ta Kung Pao, 7 January 1989). These constraining problems are quite critical to the future success of the Southern China growth triangle.

Finally, inadequate transfer of technology and infrastructure planning could also limit the long run growth and success of the growth triangle. For instance, a sizeable portion of direct investment from Hong Kong, China to the PRC is in the form of low risk, low value added products with shorter term contracts and intermediate level of technology. While the investments and technology transfer of this nature may be suitable or, perhaps, even desirable in the early phases of the 
growth triangle, in the long run, such a strategy may impede further development. With regard to infrastructure, it is not only the question of its availability but, more importantly, how and where it is made available that will facilitate the operation and implementation of growth zones. In this context, proper coordination and planning in the construction of infrastructure is critical. For instance, many small districts and port cities in the PRC had developed their water supply, electricity and port facilities based on their own requirements. This type of planning in infrastructure development may not only hinder the realisation of economies of scale but, more importantly, it may not be adequate enough to cater to the needs of the growth triangle in the future.

\section{CONCEPTUAL FRAMEWORK}

\section{Background Issues}

As indicated earlier, the new innovative concept of growth zones in recent years has attracted a great deal of attention, however, very little (if any) effort is devoted to provide a formal conceptual economic framework for the growth zones. Commenting precisely on this issue of lack of formal economic paradigm of growth triangles in the literature, a recent study by Linda Low (1996, p. 7), quite emphatically noted that:

...the growth triangle has no rigorous theory to follow... (and)

there seems (to be) no real economic concept of a growth triangle...(it is therefore) purely a marketing concept.

Indeed, a growth triangle is essentially a marketing concept but with multinationals engaged in contiguous cross border economic investments and trading activities, exploiting the factor cost differentials within a sub-regional context is quite different from the formal trading blocs. All these economic and socio-political attributes of growth triangles provide a fertile ground to explore the possibilities of setting up a theoretical framework for growth zone concept. ${ }^{8}$

It is with this perspective that this section will attempt to develop a viable and robust conceptual economic framework for a "growth zone" that may provide insight into how a broad set of economic policies initiated in one region have unintended and unanticipated consequences for the economies of all regions. Such policies include but are not limited to tariff, tax, subsidies, wages, exchange rate, infrastructure planning, foreign direct investments, etc. The proposed framework may also have obvious implications for economies of the region where there is tension between national interests on the one hand and subregional, ethnic or, sociopolitical issues on the other. The conceptual framework will be within the broad

${ }^{8}$ It should be noted that the concept of growth zones does not require any large participation from the multinationals. In fact, what may possibly make the growth zone concept relevant for the South Asia region is the participation from investors from within the region. 
methodological boundaries laid out in the theory of general economic equilibrium and as applied in current theoretical studies in the fields of international trade and economic development. ${ }^{9}$ However, in terms of formulating a diversity of institutional detail, the conceptual framework could be guided by relevant studies in political economy and economic history of the region under consideration. From a theoretical point of view, attention may be given to public goods, increasing returns to scale, marginal cost pricing equilibrium, rigid production structure and political lobbying.

\section{Conceptual Issues}

Unlike the trading bloc models, which enforce the strict adherence of similar macroeconomic fundamentals among the participating countries, the growth triangle framework, however, does not require such rigid restrictions on the member economies. As noted earlier, economies in the growth triangle could be experiencing diverse and dissimilar stages of development. In fact, such variations among the participating members in their economic fundamentals leading to the existence of differentials in per capita incomes, factor input costs (particularly the wages), the level of technological knowledge and human capital endowments are precisely the factors that not only make the growth triangle framework distinct from traditional trading bloc models but, more significantly, it provides the strength and necessary ingredients to formulate a rigorous theoretical economic framework for a growth triangle.

In addition, the assumption of immobility of all types of labour and physical capital across the countries within the trading bloc model which could be either due to prohibitive large transaction costs or national immigration and labour policies of each participating member of the bloc or a combination of the two, also makes the growth model different. As a matter of fact, within the framework of a growth triangle, skilled labour and physical capital are both considered to be mobile and the associated transaction cost with such mobility is very small, particularly due to its close geographic proximity characteristics as well as other non-economic considerations (such as similar language, common ethnicity, etc.), as noted earlier.

Other important considerations for the growth triangle framework pertain to the assumption of immobility of unskilled labour and the highly mobile character of financial capital across the region. Thus, the basic economic rationale for the relatively prosperous economies to invest (as FDI or export of both physical and financial capital as well as skilled labour) in the less developed region of a growth triangle, despite the fact that the former economies had the choice to undertake similar investments in their domestic market, is predicated on the assumption of existence of significant differential in relative return on investments. The relative return on FDI investments is again dependent on the differential in relative marginal productivities of investments between foreign and domestic markets, policy variables

${ }^{9}$ For particular theoretical aspects of the framework, the model could draw upon the work on Innis' $(1956,1972)$ staples theory in general equilibrium context and it may be related to the Caribbean school's work on plantation economies by Pryor (1982). 
(tariff, tax and subsidies) and other socio-ethnic considerations. From the point of view of the less developed region, the economic rationale is straightforward, that is, the FDI simply creates value added output and employment for the local regional economy which in turn may lead to further development of the region through infrastructure as well as transfer of technology.

In the remainder of the paper, for illustrative purposes, the theoretical framework of a growth triangle is developed considering the Southern China growth triangle. However, the analytical setting can easily be extended to other growth triangles in the Asia-Pacific region.

\section{Setting of the Framework}

The context of a growth triangle framework entails three distinct economies. Consider the Hong Kong, China economy in which there are productions of financial capital and technical skills. Financial capital, in turn, is assumed to be generated using labour and some other exogenous variables ${ }^{10}$ while the production of technical skills is based on the level of education and other exogenous education policy ${ }^{11}$ variables. Financial capital and technical skills are subsequently invested in the PRC's economy.

On the other hand, the Taiwan Province of China's economy is assumed to produce and supply capital goods in the form of machinery and equipment to China using domestic capital and labour as inputs. As indicated earlier, the economic gains to both Hong Kong, China and Taiwan Province of China are due to their potential higher return to investments in the PRC. The key element to focus on, in this context, is the determination of economic returns which is based on the expected relative marginal productivities of foreign versus domestic investments, transaction costs (geographic proximity), relevant economic policy initiatives (tariff, tax, subsidies), and other non- economic factors.

In this paper, the production hub within the growth triangle framework lies in the Southern Region of the PRC which is assumed to produce an exportable commodity using domestic inputs (unskilled labour, land, infrastructure) ${ }^{12}$ and foreign inputs (physical capital, in terms of machinery and equipment) from Hong Kong, China and Taiwan Province of China.

\footnotetext{
${ }^{10}$ It should be noted that the financial capital production could also depend on marginal rate of time preference, by the expected yields on assets and some other monetary policy variables. However, in order to keep the analysis simple within the context of a growth triangle framework we have assumed them as exogenous.

${ }^{11}$ The role of education and government policies in creating quality human capital is a new area that has attracted a great deal of attention, in the form of Endogenous Growth theory [e.g., see The Economist (1996)].

${ }^{12}$ It should be noted that infrastructure is supposed to be a public good provided by the state. In this context, a legitimate question arises as to what role a public commodity has in case of the production of a private exportable commodity. Here it is argued that a public commodity such as infrastructure provides externalities to the production of the private good. It can also be considered as Hick's neutral efficiency enhancing commodity just as in the case of endogenous growth models.
} 
Given the production structures and the price behaviour of various inputs and outputs as well as the identities in the system, it is not difficult to identify the various multifaceted linkages prevailing within and across the national boundaries of each of the three participating members of the growth triangle. Rather than getting into the technical details, in the following, an attempt will be made to identify and highlight a few important and relevant linkages and the interdependent character of the growth triangle framework using a diagramatic flow chart approach as shown in Figure $1 .^{13}$

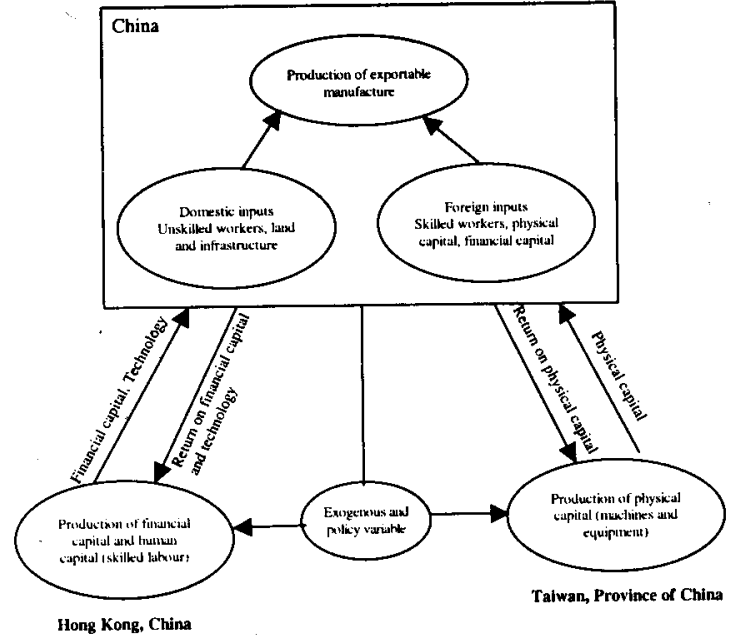

Fig. 1. Diagramatic Exposition Growth Triangle Model (GTM).

\section{Interdependent Linkages: A Diagramatic Approach}

Figure 1, which summarises the growth triangle framework, shows how the three distinct geographically contiguous economies are economically connected and interdependent through various forward and backward linkages arising from cross border trade. It is interesting to observe from Figure 1 that initially, on the face of it, it may appear that the process of FDI investments emanating either from Hong Kong, China or from Taiwan Province will have an impact on the PRC directly and the backward linkages from the PRC, due to repatriation profits, may appear to be directed only towards those two economies separately without necessarily affecting each other. However, a careful inspection of the flow chart in Figure 1, should reveal that an independent economic policy change initiated in any one or more countries could not only influence the economy of that particular country but the impact may permeate throughout the region via changes in prices of relevant variables. The theoretical model of growth triangle developed in this paper has the potential and analytical rigour to understand and identify such changes in the economic variables within and across the economies of the region.

${ }^{13}$ At this stage, more technically inclined readers may refer to Appendices B for the exact analytical specification of the growth triangle model. 
In order to further understand the impact of policy changes on the economies of a growth triangle, this paper presents an analysis of the impact of one specific policy change, namely, the infrastructure policy in the next subsection.

\section{Impact of Policy Changes: A Diagramatic Approach}

As discussed earlier, the development of infrastructure is critical for the success and sustainability of the growth triangle. In view of this, assume that the PRC authorities have undertaken a policy initiative whereby expanded port facilities as well as road transportation systems in this region have improved. Everything else being equal, the direct and first round impact of such a change in policy will be on the production of exportable goods in the PRC, as shown in Figure 2. Given the assumption of small open economy, the international price of such exportable commodity is less likely to be affected for the PRC and it is further assumed that there is a continued demand for such a product. With improved infrastructure, if the PRC economy continues to enhance its production, such increased production could initially be met through hiring more unskilled labour, thus leading to increased employment or higher wages for unskilled workers in the PRC.

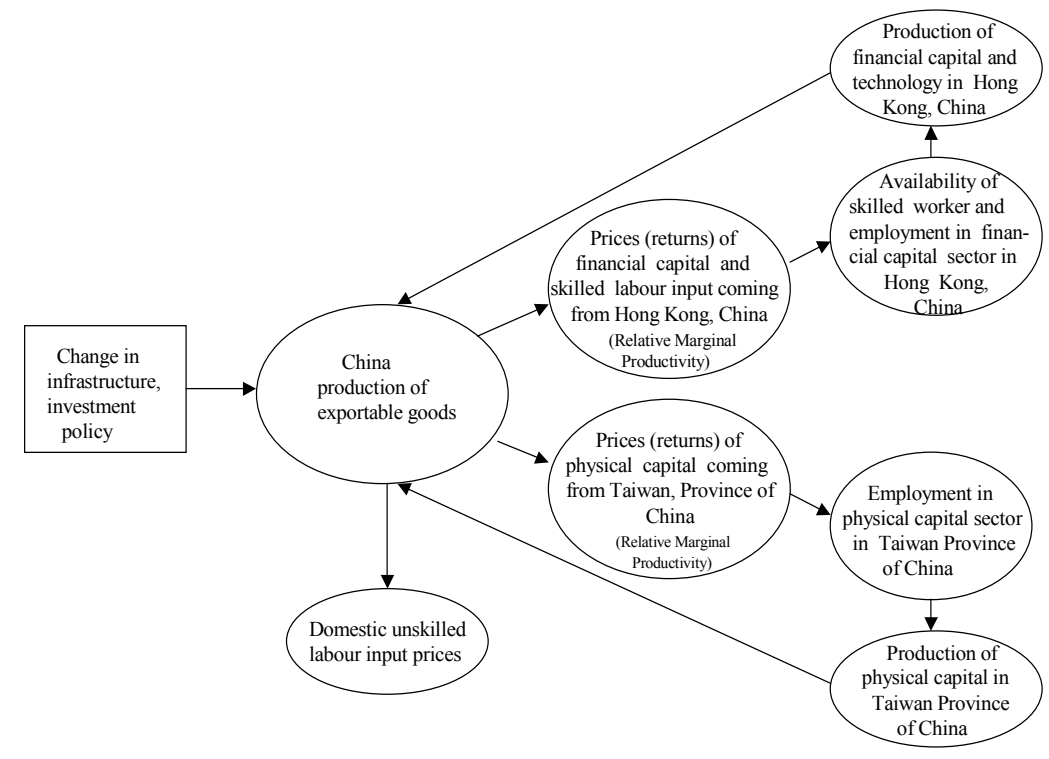

Fig. 2. Diagramatic Exposition of the Impact of Policy Change on the Economies of Growth Triangle. 
In the long run, however, the industries in the PRC may require to expand and demand more capital goods in terms of skilled workers and financial capital from Hong Kong, China as well as physical capital from Taiwan province of China. This increased demand for capital goods could impact their prices which, in turn, will motivate FDI investors from across the border in those two economies. This change in prices for capital goods, in turn, may affect the production and consequently the supply of physical capital goods from Taiwan Province of China and financial capital as well as skilled workers from Hong Kong Province of China. Obviously, the relative marginal productivities of these intermediate goods compared to their respective domestic counterpart industries will also be affected thus having an impact on prices and employment of inputs in those two economies. In the end, prices, wages, outputs (some of which are intermediate input to PRC production) and relative productivities in all economies in the growth triangle will be affected due to an initial change in the infrastructure policy. These short and long run changes in several areas were possible due to the interdependent and connected nature of the economies in the growth triangle.

\section{CONCLUDING REMARKS}

The advent of Southern China growth triangle has provided the Asia-Pacific region with a fresh and renewed source of inspiration and economic vitality and dynamism. It has also elucidated to the world that, notwithstanding, diversities and differences in economic and political systems among its members, the concept of market driven subregional growth zone is capable of according an economic climate and organisational framework for swift and sustainable economic development. While the trading bloc concept, in this context, has gained popularity in the 1970s and 1980s, concerns have been raised regarding its success and applicability; particularly in the Asia-Pacific region. Growth triangles or zones, seem to be a more viable and practically least costly option for the countries in this region and, as such, several such triangles have emerged in recent years.

Despite its eminence and the fact that a lot has been written on this subject, there still seems to be a vacuum in the growth triangle literature in terms of developing a consistent and viable theoretical framework based on rigorous economic theory. In this context, while the significance of descriptive policy oriented analysis cannot be undermined, nevertheless, it is the view of this paper that a more formal economic framework is equally significant. With this motivation and perspective, this paper has attempted to develop a consistent theoretical framework and also provided some examples of its suitability in terms of policy analysis. It should, however, be noted that every new initiative has its drawbacks in terms of not having the benefits from others, therefore, the conclusion from this paper should be viewed in that perspective. 
APPENDIX A

\section{ABBREVIATIONS AND ACRONYMS}

APEC Asia-Pacific Free Trade Area.

AFTA ASEAN Free Trade Area.

ASEAN Association of Southeast Asian Nations.

EAEC East Asian Economic Caucus.

FDI Foreign Direct Investment

SAARC South Asian Association for Regional Cooperation.

UN-ESCAP United Nations-Economic and Social Commission for Asia and the Pacific.

\section{APPENDIX B}

\section{GENERAL EQUILIBRIUM GROWTH TRIANGLE MODEL (GEGTM)}

Putting all the factors discussed under growth triangle framework in Section $\mathrm{C}$, will result in the following general equilibrium model which is named as GEGTM.

\section{(a) Optimisation Conditions}

Hong Kong, China

(1) $\left(\mathrm{L}_{\mathrm{F}}^{*}\right)$ maximises $\left(\mathrm{P}_{\mathrm{F}}^{*}-\mathrm{P}_{\mathrm{B}}\right) \mathrm{f}_{\mathrm{F}}\left(\mathrm{L}_{\mathrm{F}}, \mathrm{Z}_{\mathrm{F}}\right)-\mathrm{w}_{\mathrm{F}}{ }^{*} \mathrm{~L}_{\mathrm{F}}$; Financial Capital

(2) $\left(\mathrm{E}^{*}\right)$ maximises $\mathrm{w}_{\mathrm{T}}^{*} \mathrm{f}_{\mathrm{T}}\left(\mathrm{E}, \mathrm{Z}_{\mathrm{T}}\right)-\mathrm{P}_{\mathrm{E}} \mathrm{E}$;

Technical Skills

Taiwan Province of China

(3) $\left(\mathrm{K}_{\mathrm{C}}{ }^{*}, \mathrm{~L}_{\mathrm{C}}{ }^{*}\right)$ maximise $\mathrm{P}_{\mathrm{C}}{ }^{*} \mathrm{f}_{\mathrm{C}}\left(\mathrm{K}_{\mathrm{C}}, \mathrm{L}_{\mathrm{C}}\right)$

$$
-\mathrm{r}_{\mathrm{C}}^{*} \mathrm{~K}_{\mathrm{C}}-\mathrm{w}_{\mathrm{C}}{ }^{*} \mathrm{~L}_{\mathrm{C}}
$$

Capital Goods

PRC

(4) $\left(\mathrm{K}_{\mathrm{P}}{ }^{*}, \mathrm{~K}_{\mathrm{F}}{ }^{*}, \mathrm{~L}_{\mathrm{U}}{ }^{*}, \mathrm{~L}_{\mathrm{S}}{ }^{*}, \mathrm{~A}^{*}\right)$ maximise $\mathrm{P}_{\mathrm{E}} \mathrm{f}_{\mathrm{E}}\left(\mathrm{K}_{\mathrm{P}}, \mathrm{K}_{\mathrm{F}}, \mathrm{L}_{\mathrm{U}}, \mathrm{L}_{\mathrm{S}}, \mathrm{A}, \hat{\mathrm{I}}\right)$

$$
-\mathrm{P}_{\mathrm{C}}{ }^{*} \mathrm{~K}_{\mathrm{P}}-\mathrm{P}_{\mathrm{F}}^{*} \mathrm{~K}_{\mathrm{F}}-\mathrm{W}_{\mathrm{U}}^{*} \mathrm{~L}_{\mathrm{U}}-\mathrm{W}_{\mathrm{T}}^{*} \mathrm{~L}_{\mathrm{S}}-\mathrm{P}_{\mathrm{A}}^{*} \mathrm{~A} \text {; }
$$

Exportable Goods.

\section{(b) Production Function}

Hong Kong, China

(5) $\mathrm{F}^{*}=\mathrm{f}_{\mathrm{F}}\left(\mathrm{L}_{\mathrm{F}}^{*}, \mathrm{Z}_{\mathrm{F}}\right)$

(6) $\mathrm{T}^{*}=\mathrm{f}_{\mathrm{T}}\left(\mathrm{E}^{*}, \mathrm{Z}_{\mathrm{T}}\right)$

Taiwan Province of China

(7) $\mathrm{C}^{*}=\mathrm{K}_{\mathrm{P}}{ }^{*}=\mathrm{f}_{\mathrm{C}}\left(\mathrm{K}_{\mathrm{C}}{ }^{*}, \mathrm{~L}_{\mathrm{C}}{ }^{*}\right)$

Production function for financial capital

Production function for technology

Production function for physical capital

PRC

(8) $\mathrm{X}^{*}=\mathrm{f}_{\mathrm{E}}\left(\mathrm{K}_{\mathrm{P}}{ }^{*}, \mathrm{~K}_{\mathrm{F}}{ }^{*}, \mathrm{~L}_{\mathrm{U}}{ }^{*}, \mathrm{~L}_{\mathrm{S}}{ }^{*}, \mathrm{~A}^{*}, \hat{\mathrm{I}}\right)$

Production function for export goods.

\section{(c) Price Equations}

(9) $\mathrm{P}_{\mathrm{F}}{ }^{*}=\mathrm{f}_{\mathrm{F}}\left(\mathrm{MP}_{\mathrm{F}} / \mathrm{MP}_{\mathrm{FD}}, \mathrm{Z}_{\mathrm{F}}\right)$;

(10) $\mathrm{w}_{\mathrm{T}}^{*}=\mathrm{f}_{\mathrm{E}}\left(\mathrm{MP}_{\mathrm{T}}^{*} / \mathrm{MP}_{\mathrm{TD}}, \mathrm{Z}_{\mathrm{T}}\right)$;

(11) $\mathrm{P}_{\mathrm{C}}{ }^{*}=\mathrm{f}_{\mathrm{C}}\left(\mathrm{MP}_{\mathrm{C}}{ }^{*} / \mathrm{MP}_{\mathrm{CD}}\right)$;

Price of Financial Capital

Price of Technology

Rental Price of capital goods.

(d) Identities and Exogenous Factors

(12) $\mathrm{F}^{*}=\mathrm{K}_{\mathrm{F}}^{*}$

(13) $\mathrm{T}^{*}=\mathrm{LS}_{\mathrm{S}}^{*}$

(14) $\mathrm{C}^{*}=\mathrm{K}_{\mathrm{P}}^{*}=\mathrm{f}_{\mathrm{C}}\left(\mathrm{K}_{\mathrm{C}}{ }^{*}, \mathrm{~L}_{\mathrm{C}}{ }^{*}\right)$

(15) $\mathrm{A}^{*}=\hat{\mathrm{A}}$

Financial capital

Technology

Physical capital

Land. 
Endogenous Variables or Unknown

A Land use in PRC.

C Machinery and Capital goods production in Taiwan Province of China.

F Financial capital production in Hong Kong, China.

E Education level.

$\mathrm{K}_{\mathrm{C}}$ Capital input used to produce machinery in Taiwan Province of China.

$\mathrm{K}_{\mathrm{F}}$ Financial capital input used to produce exportable goods in the PRC.

$\mathrm{K}_{\mathrm{P}}$ Machinery and Capital inputs used to produce exportable goods in the PRC.

$\mathrm{L}_{\mathrm{C}}$ Labour input used to produce machinery in Taiwan Province of China.

$\mathrm{L}_{\mathrm{F}}$ Labour input used to produce financial capital in Hong Kong, China.

$\mathrm{L}_{\mathrm{S}}$ Skilled labour input used to produce exportable goods in the PRC.

$\mathrm{L}_{U}$ Unskilled skilled labour input used to produce exportable goods in the PRC.

$\mathrm{P}_{\mathrm{A}}$ Price of land used in the PRC.

$\mathrm{P}_{\mathrm{C}}$ Rental price of Capital and Machinery.

$\mathrm{P}_{\mathrm{F}}$ Interest on lending financial capital.

$r_{C}$ Rental price of capital in Taiwan Province of China.

$\mathrm{T}$ Technical skilled labour produced in Hong Kong, China.

$\mathrm{w}_{\mathrm{C}}$ Wage rate of labour for capital goods production in Taiwan Province of China.

$W_{F}$ Wage rate of labour for financial capital production in Hong Kong, China.

$\mathrm{w}_{\mathrm{T}}$ Wage rate or return on skilled labour.

$\mathrm{w}_{\mathrm{U}}$ Wage rate of unskilled labour.

\section{Exogenous or Policy Variables}

$\hat{A}$ Fixed quantity of land.

Î Infrastructure investments.

$P_{B}$ Borrowing interest rate in Hong Kong, China.

$\mathrm{P}_{\mathrm{E}}$ Per unit cost of education.

$Z_{\mathrm{F}}$ Monetary policy variables.

$\mathrm{Z}_{\mathrm{T}}$ Education policy variables.

The equilibrium brings out the fact that the unknowns are the output levels of production; allocation of inputs; price equations and identities in the growth triangles. More specifically, the first four optimisation conditions bring out the behavioural hypothesis that the four representative agents of the model (two from Hong Kong, China and one each from Taiwan Province of China and the PRC) are all maximisers and that they are all "small" in the conventional sense of taking the relevant prices as given parameters. It should be noted that out of the four outputs, three of them are also used as inputs. This is in keeping with the unique character of growth triangles that outputs of one region constituted imported inputs in another that provides dynamism in this framework of regional trade.

From a technical point of view, the above model has twenty unknown variables ${ }^{14}$ and six parameters given by $\left(\hat{A}, \hat{I}, Z_{F}, Z_{T}, P_{B}, P_{E}\right)$. It is important to note that the necessary conditions for maximisation furnishes nine equations obtained from maximisation problems laid out in conditions (1) to (4) in the above model. On adding the eleven equations constituting conditions (5) to (15), one obtains twenty equations to determine twenty unknowns. However, on purely technical ground a note of caution is in order. It is now well understood in the general equilibrium literature that counting equations and unknowns does not ensure that an equilibrium exists. Before undertaking the policy simulation exercise one needs to establish the viability of the general equilibrium framework. In other words, one must guarantee that the equilibrium defined above not only exists, but is locally unique and continuously differentiable in terms of its parameters, Such an analysis is, of course, outside the scope of this paper.

${ }^{14}$ The unknown variables are: $\left(\mathrm{L}_{\mathrm{F}}^{*}, \mathrm{E}^{*}, \mathrm{~K}_{\mathrm{C}}{ }^{*}, \mathrm{~L}_{\mathrm{C}}{ }^{*}, \mathrm{~K}_{\mathrm{P}}{ }^{*}, \mathrm{~K}_{\mathrm{F}}{ }^{*}, \mathrm{~L}_{\mathrm{U}}{ }^{*}, \mathrm{~L}_{\mathrm{S}}{ }^{*}, \mathrm{~A}^{*}, \mathrm{~F}^{*}, \mathrm{~T}^{*}, \mathrm{C}^{*}, \mathrm{P}_{\mathrm{F}}{ }^{*}, \mathrm{w}_{\mathrm{F}}{ }^{*}\right.$, $\left.\mathrm{w}_{\mathrm{T}}{ }^{*}, \mathrm{P}_{\mathrm{C}}{ }^{*}, \mathrm{r}_{\mathrm{C}}{ }^{*}, \mathrm{w}_{\mathrm{C}}{ }^{*}, \mathrm{w}_{\mathrm{U}}{ }^{*}, \mathrm{P}_{\mathrm{A}}{ }^{*}\right)$. 


\section{REFERENCES}

Chen, Edward K. Y., and Joseph S. L. Lee (1998) Southern China Growth Triangle: An Overview. In Myo Thant, Ming Tang and Hiroshi Kakazu (ed.) The Growth Triangles in Asia. New York: Oxford University Press.

Chia, Siow Yue, and Tsao-Yuan Lee (1992) Subregional Economic Zones: A New Motive Force in Asia-Pacific Development. Conference Paper, 20th Pacific Trade and Development, Washington, D. C.

Frankel, Jeffrey, and David Romer (1999) Does Trade Cause Growth? American Economic Review 89: 379-99.

Hasan, M. Aynul (2000) Growth Zones: An Overview, Examples and Conceptual Framework. Asia-Pacific Development Journal (forthcoming).

Innis, H. (1956) The Wheat Economy. Essays in Canadian Economic History. Toronto University Press.

Innis, H. (1972) A Defence of Tariff. Appendix to A New Theory of Value: The Canadian Economics of H. Innis, by R. Neill, Toronto University Press.

Low, Linda (1996) Government Approaches to SIJORI. Asia-Pacific Development Journal 3: 1-19.

McGee, T. G., and Scott Macleod (1992) Emerging Extended Metropolitan Regions in Asia-Pacific Urban System: A Case Study of the Singapore-Johor-Riau Growth Triangle. Conference Paper, Workshop on Asia-Pacific Urban Systems: Towards the 21st Century, The Chines University of Hong Kong, China.

Pryor, F. (1982) The Plantation Economy as an Economic System: A Review. Journal of Comparative Economics 6: 288-317.

Summers, Lawrence (1991) Regionalism and the World Trade System. Paper presented at the Federal Reserve Bank of Kansas City.

Thant, Myo, Ming Tang, and Hiroshi Kakazu (1998) Growth Triangles in Asia. New York: Oxford University Press.

The Economist (1996) The Mystery of Economic Growth. May 25-31 Issue.

Wong, Teresa Y. C. (1992) Hong Kong, China's Manufacturing Industries: Transformations and Prospects. Paper present at the Conference on Twenty-Five Years of Social and Economic Development in Hong Kong, China, The University of Hong Kong, China. 


\section{Comments}

The paper presented by M. Aynul Hasan is a useful contribution to knowledge. The author has picked an excellent real world example to illustrate the characteristics of growth zones and their welfare implications for the participating countries. The concept of growth zones is relatively new and it is indeed useful to initiate the development of a conceptual framework to analyse its theoretical underpinnings. Such a framework can also be extended in theorising and studying other modes of regional growth.

Since the paper is aimed at reviewing and understanding the nature of growth process in growth zones and taking an initial step in suggesting the broad outline of theoretical framework, there is little in the paper that can be subjected to any serious criticism. Except for a few statistical discrepancies in the information, the paper is well written and thorough in its coverage.

With these remarks, let me utilise my share of time in pointing out some directions towards developing a theoretical framework that the author may like to explore further. As far as I understand, the key feature of a growth zone is the free mobility of factors of production across a group of countries with a limited free trade in goods and non-factor services. This is just the opposite of neo-classical model of free international trade with no factor mobility. As such the model of growth zone can be regarded as the dual of free trade model. This interpretation can possibly lead to some interesting comparisons between the theories of free trade and growth zones.

One example of duality relates to the correspondence between goods prices and factor prices. Consider the factor price equivalence theorem, according to which under certain realistic assumptions, free trade in goods and non-factor services leads to reduction in disparity in factor prices across the trading countries. Therefore free trade in goods and non-factor services serves as a substitute for free mobility of labour. One should expect as a rule that under similar assumption the theory of growth zones should imply that free mobility of factors would result in equalisation of the prices of goods and non-factor services. Similar duality relations can be developed for some of the other well-known theorems in international trade.

Quaid-i-Azam University,

Eatzaz Ahmad

Islamabad. 